\title{
Healthy eating in early years settings: a review of current national to local guidance for North West England
}

\author{
Katie Bristow*, Simon Capewell, Katharine Abba, Mark Goodall and \\ Ffion Lloyd-Williams \\ Department of Health Inequalities and the Social Determinants of Health, Institute of Psychology, Health and \\ Society, University of Liverpool, Whelan Building, Brownlow Hill, Liverpool L69 3GB, UK
}

Submitted 11 May 2010: Accepted 13 December 2010: First published online 3 February 2011

\begin{abstract}
Objective: To determine the extent to which national and local UK guidelines for the early years sector address key recommendations for encouraging healthy eating based on best available evidence.

Design: Phase 1 comprised a literature review to identify new evidence to assess current relevance of the Caroline Walker Trust (CWT) 'Eating well for under- $5 \mathrm{~s}$ in child care' guidelines. Phase 2 assessed the completeness of seven local to national-level government guidelines by comparison with the 'gold standard' CWT guidelines.

Setting: Desk-based review using secondary data.

Subjects: Research literature and statutory guidelines on healthy eating in early years settings.

Results: Phase 1 retrieved seventy-five papers, of which sixty were excluded as they addressed compliance with nutritional and food-based standards only. One report examined a social marketing tool and was deemed too narrow. The remaining fourteen documents assessed interventions to encourage healthy eating in early years settings. Following quality assessment, seven documents were included. Nine key recommendations were identified: (i) role of government; (ii) early years setting policy/guidelines; (iii) training; (iv) menu planning; (v) parents; (vi) atmosphere and encouragement; (vii) learning through food; (viii) sustainability; and (ix) equal opportunities. Phase 2 identified that all seven guidelines included the nine key recommendations but sporadic cover of sub-key recommendations.

Conclusions: More detail is needed on how early years settings can encourage children to eat healthily. Research is required to develop second-layer guidance for interactive materials. Clear processes of communication and support for parents are required. Ways food relates to children's wider learning and social development need further thought, requiring collaboration between the Department of Health and the Department for Education.
\end{abstract}

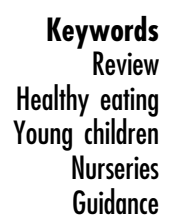

Appropriate food, energy and nutrient intakes for children under the age of 5 years are vital for their current and future health. Intakes of nutrients such as $\mathrm{Fe}, \mathrm{Zn}$ and vitamin A have specific impacts on health and development. The prevention of obesity in the early childhood period is also enormously important since this can powerfully affect health and well-being in later childhood. Furthermore, children who are obese are likely to become obese adults and suffer greatly increased risk of CVD, diabetes and many cancers ${ }^{(1-5)}$.

Given the opportunity and exposure to a healthy diet, children can learn to eat well ${ }^{(6)}$. It is therefore crucial that pre-school children are provided with nutritionally balanced meals (including snacks and drinks) and that messages about healthy eating are conveyed to parents. This is particularly true if children are to develop the knowledge, understanding and skills needed to make appropriate food choices and develop positive attitudes to a healthy $\operatorname{diet}^{(6)}$.

Young children who attend child-care settings each day may receive the majority of their energy and nutrients outside the family home ${ }^{(7)}$. In England, the number of children attending full day care increased threefold between 1997 and $2006^{(8)}$. Typically a child attending full day care can spend $10 \mathrm{~h}$ per d, $5 \mathrm{~d}$ per week for 48 weeks per year in an early years setting. Therefore, child-care settings have a responsibility to ensure that children have adequate energy and nutrient intakes as well as the right 
environment to promote positive attitudes to a healthy lifestyle.

The Department of Health (DH) in England has published a number of policy documents, service frameworks and toolkits in response to the increase in obesity, especially among children ${ }^{(9-12)}$. In 2008 the DH published Healthy Weight, Healthy Lives ${ }^{(13)}$, highlighting a need for work across early years. This statutory guidance states 'Children should be provided with healthy meals and other healthy snacks and drinks as appropriate' (p. 27) but gives no further details. Similarly, while new nutrientbased standards for school lunches have been in force for primary and secondary schools since September 2008 and 2009 respectively ${ }^{(14)}$, guidance for under-5s' childcare settings recommends only that the food and drinks provided should be healthy and nutritious ${ }^{(15)}$.

In 1998 the public health nutrition charity the Caroline Walker Trust (CWT) published the first nutritional and practical guidelines around eating in the UK for preschool child care, 'Eating well for under- $5 \mathrm{~s}$ in child care'. The CWT provides an extensive range of resources and guidance concerning healthy eating. The 'Eating well for under- $5 \mathrm{~s}$ in child care' publication is specifically for daycare settings and provides nutritional and practical advice for infants, toddlers and pre-school children. Table 2 in the present paper provides an overview of the scope and content of this resource; it is also downloadable at http:// www.cwt.org.uk/publications.html\#under5 together with a learning materials publication for people working with under- $5 \mathrm{~s}$ in child care.

The CWT guidelines were subsequently updated and relaunched in $2006^{(16)}$; they are now seen as the 'gold standard' for school meals ${ }^{(17)}$ and the main reference for early years nutrition in the $\mathrm{UK}^{(18,19)}$. Comprehensive guides have been produced by the Scottish Executive ${ }^{(20)}$, the Welsh Assembly $^{(21)}$ and the Health Promotion Agency of Northern Ireland $^{(22)}$. All such guidelines summarise and apply basic nutritional information available to all, and then add information from best practice on how to encourage healthy eating from experts in the field, in particular the CWT. The $\mathrm{DH}$ for England has not as yet produced such written guidance. However, there is activity at regional level and at local primary care trusts (PCT) and local authorities in England.

Given the increased attention directed at developing ways to encourage healthy eating in pre-schools and the as yet uneven approach to statutory guidance, the current paper aims to determine the extent to which national and local UK guidelines for the early years sector address key recommendations based on the CWT healthy eating guidelines for under-5s. This is achieved in two stages: (i) a mixed-method literature review to identify new evidence to augment the CWT 'Eating well for under- $5 \mathrm{~s}$ in child care' guidelines (Phase 1); and (ii) an assessment of healthy eating guidelines for the early years sector produced by local to national-level government, using the CWT guidelines as the 'gold standard' (Phase 2).

\section{Methods}

\section{Phase 1}

\section{Review of literature}

This review of the literature was not intended to be a formal systematic review. The methods used were devised to be as rigorous and systematic as possible. The review was considered appropriate to identify and collate any new evidence concerning healthy eating practices given that the CWT guidelines were published over 4 years ago.

\section{Inclusion criteria}

Documents were considered for inclusion if they made recommendations for interventions to encourage healthy eating in pre-school settings, based on convincing evidence presented in the document. Published and unpublished quantitative and qualitative studies and systematic reviews were eligible, provided that they met the required quality standards (detailed in the 'Quality assessment' section).

The following subjects were included: children aged between 2 and 5 years, AND (experiences of eating in pre-school child-care settings OR facilitators, barriers and potential barriers to enabling the provision of healthy food OR policy and practice recommendations to improve healthy eating in pre-school settings). Literature relating to dental health or breast-feeding and weaning were excluded. While dental caries and infant feeding are both important issues, they did not fall within the focus of the present paper to evaluate practical guidance on the ways to encourage young children to eat healthily.

Other criteria for inclusion were: published 1999 to June 2009; written in English; and undertaken in a highincome country.

\section{Search methods}

The search was conducted using PubMed, Scopus and a hand search. Key search terms included 'food', 'nutrition', 'diet', 'pre-school', 'under-five', 'child*', 'nursery', 'day care', 'children's centre', 'kindergarten', 'policy', 'practice', 'strategy', 'guidelines' and 'recommendations'. These were refined in the first instance in PubMed as MeSH terms and then adapted for Scopus. The terms 'dental health promotion', 'dental caries and oral health', 'breastfeeding' and 'weaning' were excluded.

\section{Quality assessment}

For quality assessment purposes, documents were divided into three main types: (i) published studies; (ii) systematic reviews; and (iii) published online reports of surveys.

Published studies were systematically assessed by M.G. for risk of bias in eight areas as appropriate to the type of study: (i) sample size; (ii) randomisation; (iii) response; (iv) follow-up; (v) measurement instrument; (vi) measurement observer; (vii) sample characteristics; and (viii) incentives. 
From this systematic assessment, an overall qualitative judgement of risk of bias was made and only those studies judged to have a low risk of bias were included.

Systematic reviews were assessed by K.A. and selected for inclusion if they had a clear systematic approach in terms of search strategy, inclusion criteria, outcomes of interest, quality assessment and data extraction, and a clear presentation of findings and conclusions.

Published online survey reports were assessed by K.B. and were included if they were particularly relevant to the question their methods clearly stated.

\section{Phase 2}

Evaluation of local, regional and national guidelines for supporting bealthy eating in under-5s

Selected guidelines were independently assessed by two authors (K.B. and F.L.-W.) for inclusion of each of the key and sub-key recommendations identified through Phase 1 , using a checklist as a guide. The comprehensiveness of the recommendations rather than the clarity and quality was assessed. It was felt that the latter variables would require a qualitative assessment of how the recommendations were implemented in practice.

The Scottish Executive ${ }^{(20)}$ and Welsh Assembly ${ }^{(21)}$ guidelines were included to represent the national level, as England does not as yet have national-level guidelines and the Northern Ireland guidelines ${ }^{(22)}$ were published prior to the updated CWT guidelines. Guidelines from North West England included one produced at regional level and four produced by local authorities or PCT in Merseyside. In order to maintain anonymity, the reference numbers for the regional and local-level guidelines have not been used when presenting the results in Table 3 .

\section{Results and analysis}

\section{Pbase 1}

\section{Results}

Seventy-five documents were retrieved through the search. Of these, sixty were excluded because they addressed compliance with nutritional and food-based standards only and not practical guidance to encourage healthy eating. One document looked at a specific intervention using a social marketing tool and was deemed too narrow to be included ${ }^{(23)}$. The remaining fourteen documents $^{(24-39) *}$ assessed interventions to encourage healthy eating in pre-school settings and were therefore provisionally included and assessed for quality; these included seven study documents, two systematic reviews and five surveys. Following assessment of quality, two published studies ${ }^{(26,29)}$ were excluded because they

\footnotetext{
* References 37 to 39 refer to the same study, so have been treated as one
} throughout.
Table 1 Number of documents selected for review

\begin{tabular}{lcccc}
\hline & $\begin{array}{c}\text { Research } \\
\text { papers }\end{array}$ & $\begin{array}{c}\text { Systematic } \\
\text { reviews }\end{array}$ & $\begin{array}{c}\text { Survey } \\
\text { reports }\end{array}$ & Total \\
\hline Total & 7 & 2 & 5 & 14 \\
Excluded & 5 & 0 & 2 & 7 \\
Included & 2 & 2 & 3 & 7 \\
\hline
\end{tabular}

provided insufficient detail to adequately assess their methods and three were excluded because they were assessed as having a high risk of bias ${ }^{(24,27,34)}$. Seven documents were finally included in the review. These included two published studies by Talvia et al. and Williams et al. $^{(36-39)}$; two systematic reviews by Campbell and Hesketh and the Mother and Infant Research Unit ${ }^{(25,30)}$; and three surveys published online. The latter included two reports from the Office for Standards in Education (Ofsted), Starting Early and Food for Thought ${ }^{(31,32)}$. These surveys were included because of the important statutory role this body plays in early years settings. A baseline survey conducted by a local authority in the region ${ }^{(35)}$ was also included as it was deemed to be of particular relevance to local authorities and PCT in the North West.

Table 1 summarises the number of documents initially identified as relevant and the number excluded following quality assessment.

\section{Analysis}

A qualitative thematic approach ${ }^{(40)}$ to analysis was used to develop the key themes relating to encouraging healthy eating in pre-school settings. Word documents were created of the recommendations from each of the seven documents. These were uploaded into the software NVivo 8 (QSR International (UK) Ltd, Southport, UK) for coding. The CWT guidelines were analysed separately using the same process. The included CWT guidelines, reports and studies were then further explored under each key theme to identify sub-themes.

The seven included documents ${ }^{(25,30-32,35-39)}$ and the CWT 'Eating well for under- $5 \mathrm{~s}$ in child care' guidelines were analysed by K.B. and F.L.-W. to identify key themes relating to recommendations to promote healthy eating in pre-school settings.

Once saturation $^{(41)}$ was achieved, a final list of overarching themes was established: (i) role of government; (ii) early years setting policy/guidelines; (iii) training; (iv) menu planning; (v) parents; (vi) atmosphere and encouragement; (vii) learning through food; (viii) sustainability; and (ix) equal opportunities, and sub-themes within the themes. Given the focused nature of the literature review there were no major differences between the themes identified by K.B. and F.L.-W. The identified themes and sub-themes are presented in Table 2.

An important finding from the exercise of identifying key recommendations from the seven studies ${ }^{(25,30-32,35-39)}$ was the confirmation of the continuing relevance of the 
Table 2 Key themes and sub-themes for developing a healthy eating environment in pre-school settings

\begin{tabular}{|c|c|c|}
\hline & $\mathrm{CWT}^{(16)}$ & $\begin{array}{l}\text { Other studies } \\
\text { (reference nos.) }\end{array}$ \\
\hline \multicolumn{3}{|l|}{ Role of government } \\
\hline Maker and enforcer of relevant legislation & $\boldsymbol{}$ & $x$ \\
\hline Instigator of institutional change & $\boldsymbol{}$ & 37-39 \\
\hline \multicolumn{3}{|l|}{ Early years setting policy/guidelines } \\
\hline $\begin{array}{l}\text { Early years settings should have their own guidelines for food and nutrition and menu } \\
\text { planning }\end{array}$ & レ & 31 \\
\hline \multicolumn{3}{|l|}{ Training } \\
\hline $\begin{array}{l}\text { All staff should go on the appropriate training courses for their specific involvement } \\
\text { in encouraging healthy eating }\end{array}$ & レ & $30,31,35,37-39$ \\
\hline \multicolumn{3}{|l|}{ Menu planning } \\
\hline Relevant staff to have training in menu planning; CWT suggests parents also & レ & 35 \\
\hline Input to be sought from dietitians and other experts such as environmental health officers & $x$ & 32 \\
\hline \multicolumn{3}{|l|}{ Parents } \\
\hline $\begin{array}{l}\text { Parents and carers should work in partnership and communicate regularly to encourage } \\
\text { healthy eating }\end{array}$ & $\boldsymbol{}$ & 31,32 \\
\hline Parents to be supported to reinforce messages at home & $x$ & $30,37-39$ \\
\hline Involve parents in menu planning & レ & $x$ \\
\hline Provide parents with guidelines & $\boldsymbol{}$ & $x$ \\
\hline Provide opportunities to increase parental knowledge through meetings/workshops, etc. & $x$ & $30,37-39$ \\
\hline \multicolumn{3}{|l|}{ Atmosphere and encouragement } \\
\hline Awareness of staff and parents as role models & レ & $x$ \\
\hline Awareness that eating is an important part of social skills development & $\boldsymbol{}$ & $x$ \\
\hline Involving children in the preparation and serving of meals & レ & $x$ \\
\hline Presentation of food is appropriate 1 - to 5 -year-olds & $x$ & 32 \\
\hline Awareness of ways to encourage children to eat, dealing with fussy eaters and refusal & レ & $x$ \\
\hline Time and lengths of meals are appropriate for this age group & レ & $x$ \\
\hline Rewards and celebrations (birthdays, etc.) should use alternatives to sweets and cakes & $\boldsymbol{\nu}$ & $x$ \\
\hline \multicolumn{3}{|l|}{ Learning through food } \\
\hline Learning about food can be used as a lead into wider learning & レ & $x$ \\
\hline It can increase the child's experience of food & レ & $x$ \\
\hline Links to social skill development & レ & $x$ \\
\hline Specific holidays and festivals are a good way to introduce learning through food & $\boldsymbol{}$ & $x$ \\
\hline Developmentally appropriate methods should be used & $x$ & $37-39$ \\
\hline Use a multimedia approach & $x$ & 30 \\
\hline \multicolumn{3}{|l|}{ Sustainability } \\
\hline Consideration given to environmental issues such as using locally produced foods & $\boldsymbol{}$ & $x$ \\
\hline \multicolumn{3}{|l|}{ Equal opportunities } \\
\hline $\begin{array}{l}\text { All relevant aspects of social cultural diversity should be kept in mind: gender, disability, } \\
\text { ethnicity, religion, special diets (diabetes, allergies, etc.) }\end{array}$ & レ & $25,31,37-39$ \\
\hline
\end{tabular}

CWT, Caroline Walker Trust; $\boldsymbol{}$, theme/sub-theme is included in the guidelines; $\mathbf{x}$, theme/sub-theme is not included in the CWT guidelines or addressed in the studies.

CWT guidelines. There were only a few areas where the evidence from the reviewed documents added to the CWT guidelines: menu planning advice could be sought from dietitians and other experts ${ }^{(32)}$; nurseries could provide opportunities to increase parental knowledge $\mathrm{e}^{(30,37-39)}$; food should be presented appropriately for under- $5 \mathrm{~s}^{(32)}$; developmentally appropriate early years methods should be used to encourage learning ${ }^{(32)}$; and linked to this, a need for a multimedia approach to be taken ${ }^{(30)}$. While these are all relevant recommendations they confirm the salience of the CWT guidelines.

\section{Pbase 2}

Evaluation of local, regional and national guidelines for supporting bealthy eating in under-5s

England does not as yet have national-level guidelines. The Northern Ireland guidelines ${ }^{(22)}$ were published in 2005 prior to the CWT guidelines in 2006. Therefore the Scottish Executive $^{(20)}$ and Welsh Assembly ${ }^{(21)}$ guidelines were included to represent the national level. The guidelines from the North West included one produced at regional level and four produced by local authorities or PCT in Merseyside. Each guideline was independently assessed by K.B. and F.L.-W. for evidence of the key and sub-key recommendations.

The findings from the evaluation are reported under each of the key recommendations, with Table 3 indicating whether a specific set of guidelines included a particular sub-recommendation. Occasionally, sub-themes appear to be repeated across key recommendations; this is in order to emphasise particular aspects, e.g. involving parents in menu planning.

\section{Role of government}

All seven guidelines report that government should create and enforce relevant legislation. In terms of instigating 
Table 3 Evaluation of local, regional and national guidelines for supporting healthy eating in under-5s

\begin{tabular}{|c|c|c|c|c|c|c|c|}
\hline & $\begin{array}{l}\text { Scottish } \\
\text { Executive }^{(20)}\end{array}$ & $\begin{array}{l}\text { Welsh } \\
\text { Assembly }\end{array}$ & $\begin{array}{c}\text { Regional } \\
\text { (North West) }\end{array}$ & Local $1^{*}$ & Local 2 & Local 3 & Local 4 \\
\hline \multicolumn{8}{|l|}{ Role of government } \\
\hline Maker and enforcer of relevant legislation & $\boldsymbol{\nu}$ & $\boldsymbol{V}$ & $\boldsymbol{r}$ & $\boldsymbol{r}$ & $\boldsymbol{\nu}$ & $\boldsymbol{}$ & $\boldsymbol{}$ \\
\hline Instigator of institutional change & & & $\boldsymbol{\nu}$ & $\boldsymbol{\nu}$ & $\boldsymbol{\nu}$ & $\boldsymbol{\nu}$ & レ \\
\hline \multicolumn{8}{|l|}{ Early years setting policy/guidelines } \\
\hline $\begin{array}{l}\text { Early years settings should have their own guidelines for food and nutrition and } \\
\text { menu planning }\end{array}$ & レ & レ & レ & レ & レ & レ & レ \\
\hline \multicolumn{8}{|l|}{ ( S - } \\
\hline $\begin{array}{l}\text { All staff should go on the appropriate training courses for their specific involvement } \\
\text { in encouraging healthy eating } \\
\text { Information }\end{array}$ & レ & $\boldsymbol{\nu}$ & $\boldsymbol{r}$ & $\boldsymbol{r}$ & レ & $\boldsymbol{r}$ & レ \\
\hline Healthy eating information should be included as part of wider strategies & $\boldsymbol{\nu}$ & & & & & $\boldsymbol{\nu}$ & $\boldsymbol{r}$ \\
\hline \multicolumn{8}{|l|}{ Menu planning } \\
\hline $\begin{array}{l}\text { Relevant staff to have training in menu planning; CWT suggests parents also } \\
\text { Input to be sought from dietitians and other experts such as environmental health officers }\end{array}$ & レ & $\boldsymbol{V}$ & $\boldsymbol{\nu}$ & $\boldsymbol{\nu}$ & & & $\boldsymbol{\nu}$ \\
\hline \multicolumn{8}{|l|}{ Parents } \\
\hline $\begin{array}{l}\text { Parents and carers should work in partnership and communicate regularly to encourage } \\
\text { healthy eating }\end{array}$ & $\boldsymbol{V}$ & レ & $\boldsymbol{r}$ & $\boldsymbol{V}$ & $\boldsymbol{V}$ & $\boldsymbol{r}$ & $\boldsymbol{V}$ \\
\hline Parents to be supported to reinforce messages at home & $\boldsymbol{\nu}$ & & & $\boldsymbol{\nu}$ & & & \\
\hline Involve parents in menu planning & $\boldsymbol{\nu}$ & $\boldsymbol{\nu}$ & & $\boldsymbol{\nu}$ & & $\boldsymbol{\nu}$ & $\boldsymbol{\nu}$ \\
\hline Provide parents with guidelines & & $\boldsymbol{\nu}$ & & $\boldsymbol{\nu}$ & & & \\
\hline Provide opportunities to increase parental knowledge through meetings/workshops, etc. & & & & $\boldsymbol{\swarrow}$ & & $\boldsymbol{\swarrow}$ & レ \\
\hline \multicolumn{8}{|l|}{ Atmosphere and encouragement } \\
\hline Awareness of staff and parents as role models & レ & レ & & $\boldsymbol{レ}$ (staff only) & & & レ (staff only) \\
\hline Awareness that eating is an important part of social skills development & $\boldsymbol{\swarrow}$ & $\boldsymbol{\nu}$ & & & $\boldsymbol{\nu}$ & $\boldsymbol{\swarrow}$ & $\boldsymbol{\nu}$ \\
\hline \multirow{2}{*}{\multicolumn{8}{|c|}{ Presentation of food is appropriate 1 - to 5 -year-olds }} \\
\hline & & & & & & & \\
\hline Awareness of ways to encourage children to eat, dealing with fussy eaters and refusal & & $\boldsymbol{\nu}$ & & $\boldsymbol{\nu}$ & & & \\
\hline Time and lengths of meals are appropriate for this age group & $\boldsymbol{\nu}$ & $\boldsymbol{V}$ (parents only) & & & & & \\
\hline Rewards and celebrations (birthdays, etc.) should use alternatives to sweets and cakes & & & レ & $\boldsymbol{V}$ & レ & & $\boldsymbol{V}$ \\
\hline \multicolumn{8}{|l|}{ Learning through food } \\
\hline Learning about food can be used as a lead into wider learning & & レ & & $レ$ (vague) & & & $\boldsymbol{V}$ \\
\hline It can increase the child's experience of food & $\boldsymbol{\swarrow}$ & & & & & & $\boldsymbol{\swarrow}$ \\
\hline Links to social skill development & $\boldsymbol{\swarrow}$ & & & & $\boldsymbol{\nu}$ & $\boldsymbol{\nu}$ & $\boldsymbol{\nu}$ \\
\hline Specific holidays and festivals are a good way to introduce learning through food & & & & & & & $\boldsymbol{\swarrow}$ \\
\hline Developmentally appropriate methods should be used & & & & & & & $\boldsymbol{V}$ \\
\hline Use a multimedia approach & & & & & & & \\
\hline \multicolumn{8}{|l|}{ Sustainability } \\
\hline Consideration given to environmental issues such as using locally produced foods & & $\boldsymbol{\nu}$ & $\boldsymbol{\nu}$ & & & & $\boldsymbol{\nu}$ \\
\hline \multicolumn{8}{|l|}{ Equal opportunities } \\
\hline $\begin{array}{l}\text { All relevant aspects of social cultural diversity should be kept in mind: gender, disability, } \\
\text { ethnicity, religion, special diets (diabetes, allergies, etc.) }\end{array}$ & レ & $\boldsymbol{V}$ & $\boldsymbol{V}$ & $\boldsymbol{V}$ & $\boldsymbol{r}$ & $\boldsymbol{V}$ & $\boldsymbol{V}$ \\
\hline
\end{tabular}

CWT, Caroline Walker Trust; $\boldsymbol{V}$, theme/sub-theme is included in the guidelines.

*In order to maintain anonymity, the term 'local' has been used for the guidelines produced by the four North West primary care trusts and/or local governments. 
institutional change, only the regional and local-level guidelines suggest that governmental agencies should take on this role.

\section{Early years setting policy/guidelines}

All the guidelines recommend that early years settings develop their own healthy eating guidelines/policies. In addition, some of the guidelines at national level and the local guidelines give further practical support including an example of an appropriate policy.

\section{Training}

All guidelines at national, regional and local level identify training for staff as important, although some state this more explicitly than others. The Welsh guidelines, for example, give details of relevant training courses such as the Open Colleges network courses. These guidelines also have a checklist of questions such as 'Do you have a nutrition and oral health training policy?' and 'Have staff had advice and guidance on nutrition in early years?'

\section{Menu planning}

Only the national-level guidelines explicitly state the need for staff to receive training in menu planning. Input from dietitians and other experts is recommended by the regional and the first local guideline regarding special dietary requirements. The fourth local guideline names such experts as their partners in developing healthy eating in early years settings.

\section{Parents}

All government levels recommend that early years settings and parents should work together and communicate regularly to encourage healthy eating in young children. The Scottish national and the third and fourth local guidelines identify the importance of communication, whether this is between parents and the early years providers and/or between the relevant statutory services. Most of the guidelines propose that the settings can support parents' own knowledge and awareness of healthy eating and through this encourage healthy eating in the home environment. The fourth local guideline aims 'to raise awareness of health eating, promote oral health and food safety issues amongst parents/carers...' and expects as an outcome that parents and the setting will work closer together using a consistent approach to healthy eating. The first, third and fourth local guidelines encourage parental learning via parents evenings and/or specific workshops.

\section{Atmosphere and encouragement}

As shown in Table 3, no sub-recommendation was fully covered by all guidelines. With regard to the need for the timing and length of meal times to be appropriate to this age, only the national guidelines indicate this is relevant. The regional and three out of the four local guidelines mention the need to use alternatives to sweets and cakes for rewards and celebrations. Only the Welsh and the first local guideline discuss ways to encourage fussy eaters. None of the guidelines raise the importance of presenting food in age-appropriate ways.

\section{Learning through food}

Interestingly, given all of the guidelines had been developed to link into the Department for Children, Schools and Families (DCSF; now the Department for Education) Early Years Foundation Stage (EYFS) strategy ${ }^{(15)}$, only the fourth local guideline appears to have a wider vision for food-related learning. A key learning focus would seem to be the role meal times can play in social skill development; however, this is raised only by the Welsh, second, third and fourth local guidelines. Again despite the connection with EYFS, none of the guidelines mention using a multimedia approach to encourage healthy eating with young children.

\section{Sustainability}

In terms of environmental sustainability (e.g. carbon footprint and sustainable fishing) only three guidelines include this, those being the Welsh national, regional and fourth local. Regarding sustainability in terms of the balance between cost, quality and quantity, this is noted by just the second and fourth local guidelines.

\section{Equal opportunities}

All of the guidelines are in agreement that equal opportunities are important across a comprehensive range of factors including gender, ethnicity, disability, religion and specific health-related needs.

\section{Discussion}

The assessment of governmental guidelines suggests that all nine key recommendations of the CWT guidelines are deemed relevant by all levels of government at local, regional and national level. This was reassuring. However, there was much less consensus on which subthemes to include and the depth of detail of the guidance. There seems to be unanimous agreement that all early years settings need to have their own healthy eating guidelines/policies, staff need training and that equal opportunities is addressed. In some cases recommendations were backed up with extra information such as an example of a healthy eating policy or details of training courses. This additional input may act as an extra lever to support settings in their healthy eating aspirations. Specific training in menu planning is suggested by both national guidelines, while other guidance notes the need for input from dietitians and other experts.

There was a consensus across the government guidelines about the need for regular communication and 
co-operation between the early years setting and parents/ carers. Interestingly, a significant finding from the associated primary study ${ }^{(42)}$ indicates that clear regular communication between the local PCT and Ofsted inspectors is important to prevent conflicting messages.

Apart from the need to communicate regularly with parents there is some agreement that the early years setting may have a wider role in supporting parents to reinforce appropriate messages and practice in the home. This is in line with the recommendations from three of the seven studies in Phase $1^{(25,30,37-39)}$ and the associated research ${ }^{(42)}$. However further research would be needed to ascertain the feasibility of such an initiative.

Written recommendations alone are not likely to have the impact to enable practitioners to find ways to encourage children to eat at meal times. Therefore it is perhaps understandable that the government guidelines varied in terms of the emphasis on what is appropriate to include. For the national guidelines it was age-appropriate timing and length of meal times, with regional and local guidelines mentioning using alternative rewards to sweets and cakes for celebrations. How to encourage children who are being fussy at meal times is clearly something that requires demonstration and practice, and cannot be conveyed in the written word only. However, only two of the guidelines mention ways to encourage fussy eaters to eat and none mention food presentation. This needs further consideration, as does the potential for guidelines to be linked to a dedicated set of interactive learning materials. Assessment of the format of the guidelines was not within the scope of the present paper. However, the authors suggest that research is needed to explore what is the most effective format to encourage guidelines to be implemented.

Despite the explicit association with education and learning through $\mathrm{EYFS}^{(15)}$, the potential for food and meal times to be an integral part of a young child's progress towards Key Stage competencies, including social skills development, were explored by only some of the guidelines. This is another area in which further research involving collaborations between the $\mathrm{DH}$ and the Department for Education could yield improvements in healthy eating knowledge, attitudes and behaviour, with possible long-term influence on current cohorts of under$5 \mathrm{~s}$ and future generations.

While safeguarding the environment may not be the concern of governmental guidelines in the short term, it would seem to be something that all levels of government need to promote and again represents an area where different governmental departments need to be working together more concertedly.

While we attempted to be systematic in conducting the review of the literature herein, there is no claim that a systematic review process was adopted. Indeed given the wide range of studies, surveys and reports included it would not have been possible to keep to the narrow criteria of a traditional systematic review. Once the final seven studies were identified a qualitative process was employed to look for emerging themes that could be integrated with the CWT 2006 healthy eating for under5 s guidance to make a list of key and sub-key recommendations. No inference is intended to suggest this is necessarily a definitive list; alternatively we suggest that all of the key recommendations have merit. The process enabled a reasonable degree of confidence when it came to Phase 2 of the paper to assess the extent to which the recommendations were included in national, regional and local healthy eating guidelines in early years settings.

\section{Conclusions}

To our knowledge, the present paper is the first to determine the extent to which national and local governmental guidelines developed in the UK address the key recommendations arising from the CWT 'Eating well for under-5s in child care' guidelines ${ }^{(16)}$. All reviewed guidelines included the nine key recommendations; however, there was sporadic cover of sub-key themes. Given the pertinence of both the key and subrecommendations it would seem important that all be included in government guidelines. Furthermore, a clear process for communication with and support for parents in encouraging healthy eating needs to be stated in guidelines. More detail is also needed on how to work with children who are reluctant to eat. Recommendations should also link into research on developing a second layer of guidance in the form of appropriate interactive materials. This evaluation has also drawn attention for more work to be done on ways food and meal times can be made more central to young children's wider learning, as well as to development of social skills. This would require greater collaboration between the $\mathrm{DH}$ and Department for Education.

\section{Acknowledgements}

This paper is the original work of the authors, has not been published elsewhere and is not being considered for publication by another journal. The research to which this paper is related was supported by the Liverpool Institute of Health Research (formerly MerseyBeat). There are no known conflicts of interest. K.B. researched, reviewed and analysed the literature; S.C. read and made editorial comments; K.A. and M.G. assessed the quality of the research literature and made editorial comments; F.L.-W. contributed to the analysis and made editorial comments. The authors would like to thank all the members of the research steering committee for their invaluable advice. 


\section{References}

1. Bundred P, Kitchiner D \& Buchan I (2001) Prevalence of overweight and obese children between 1989 and 1998: population based series of cross sectional studies. BMJ 322, 326-328.

2. Goran MI (2001) Metabolic precursors and effects of obesity in children: a decade of progress, 1990-1999. Am J Clin Nutr 73, 158-171.

3. Kotani K, Nishida M, Yamashita S et al. (1997) Two decades of annual medical examinations in Japanese obese children: do obese children grow into obese adults? Int $J$ Obes Relat Metab Disord 21, 912-921.

4. Whitaker RC, Wright JA, Pepe MS et al. (1997) Predicting obesity in young adulthood from childhood and parental obesity. $N$ Engl J Med 337, 869-873.

5. Caballero B (2001) Early nutrition and risk of disease in the adult. Public Health Nutr 2, 335-336.

6. Thomas J, Sutcliffe K, Harden A et al. (2003) Children and Healthy Eating: A Systematic Review of Barriers and Facilitators. London: EPPI-Centre, Social Science Research Unit, Institute of Education, University of London; available at http://eppi.ioe.ac.uk/EPPIWebContent/hp/reports/healthy_ eating02/Final_Report_web.pdf

7. Pre-school Learning Alliance (2006) Act Now to bridge the early years nutrition gap says Alliance, as it launches new training scheme for practitioners. Press release, 26 January. http://www.pre-school.org.uk/media/press-releases/54/actnow-to-bridge-the-early-years-nutrition-gap-says-alliance-asit-launches-new-training-scheme-for-practitioners (accessed January 2009).

8. Foresight (2007) Tackling Obesity: Future Choices - Project Report, 2nd ed. London: Government Office for Science, Department of Innovation Universities and Skills; available at http://www.bis.gov.uk/assets/bispartners/foresight/ docs/obesity/17.pdf

9. Department of Health, The Information Centre for Health and Social Care (2010) National Child Measurement Programme: England, 2009/10 school year. http://www. ic.nhs.uk/webfiles/publications/003_Health_Lifestyles/ncmp/ NCMP_2009-10_report.pdf (accessed January 2011).

10. Department of Health (2004) Choosing Health: Making Healthier Choices Easier. London: The Stationery Office; available at http://webarchive.nationalarchives.gov.uk/+/ www.dh.gov.uk/en/Publicationsandstatistics/Publications/ PublicationsPolicyAndGuidance/DH_4094550

11. Department for Education and Skills\& Department of Health (2006) National Service Framework for Children, Young People and Maternity Services: The Mental Health and Psychological Wellbeing of Children and Young People. London: DH Publications; available at http://www. dh.gov.uk/prod_consum_dh/groups/dh_digitalassets/@dh/ @en/documents/digitalasset/dh_4090560.pdf

12. Swanton K \& Frost M (2007) Lightening the Load: Tackling Overweight and Obesity. A Toolkit for Developing Local Strategies to Tackle Overweight and Obesity in Children and Adults. London: National Heart Forum in association with the Faculty of Public Health; available at http:// www.kentsport.org/pdfs/obesity_toolkit_full.pdf

13. Cross-Government Obesity Unit, Department of Health \& Department of Children, Schools and Families (2008) Healthy Weight, Healthy Lives: A Cross-Government Strategy for England. London: DH Publications; available at http://www.dh.gov.uk/prod_consum_dh/groups/dh_ digitalassets/documents/digitalasset/dh_084024.pdf

14. Department for Children, Schools and Families (2005) Nutritional Standards for School Lunches and Other School Food. Final Decisions on the Report of the School Meals Review Panel on School Lunches and the Advice of the School Food Trust on Other School Food. London: DCSF; available at http://media.education.gov.uk/assets/files/pdf/ s/school $\% 20$ food $\% 20$ trust $\% 20-020$ nutritional $\% 20$ standards $\%$ 20for\%20school\%20lunches.pdf

15. Department for Children, Schools and Families (2010) Early Years Foundation Stage Framework. http://nationalstrategies. standards.dcsf.gov.uk/search/earlyyears/results/nav: 46528 (accessed March 2010).

16. Crawley H (2006) Eating Well for Under-5s in Child Care: Practical Nutritional Guidelines, 2nd ed. St Austell: Caroline Walter Trust; available at http://www.cwt.org.uk/pdfs/ Under5s.pdf

17. School Food Trust (2005) Turning the Tables: Transforming School Food - A Report on the Development and Implementation of Nutritional Standards for School Lunches. Prepared by the School Meals Review Panel. London: DCSF; available at http://www.schoolfoodtrust. org.uk/UploadDocs/Library/Documents/SMRP_Report_ FINAL.pdf

18. Department for Children, Schools and Families \& School Food Trust (2010) Guidance for Food and Drink Provision in Early Years Settings (March 2010). London: DCSF; available at http://www.schoolfoodtrust.org.uk/download/ documents/pdf/early_years_food_and_nutrition_guidance.pdf

19. National Institute for Health and Clinical Excellence (2008) Improving the Nutrition of Pregnant and Breastfeeding Mothers and Children in Low-income Housebolds. NICE Public Health Guidance no. 11. London: NICE; available at http://www.nice.org.uk/nicemedia/live/11943/40097/ 40097.pdf

20. Scottish Executive (2006) Nutritional Guidance for Early Years: Food Choices for Children Aged 1-5 Years in Early Education and Childcare Settings. Edinburgh: Scottish Executive; available at http://www.scotland.gov.uk/ Resource/Doc/89729/0021563.pdf

21. Welsh Assembly Government (2009) Food and Health Guidelines for Early Years and Childcare Settings. Cardiff: Welsh Assembly Government; available at http://wales. gov.uk/docs/phhs/publications/foodandhealth/090414 guidelinesen.pdf

22. Health Promotion Agency for Northern Ireland (2005) Nutrition Matters for the Early Years: Guidance for Feeding the Under Fives in Childcare. Belfast: HPAfNI; available at http://www.hpani.org/Resources/nutrition/pdfs/nutmatters 2006.pdf

23. Winters L (2009) Evaluation of the Phase 2 Snack Right Social Marketing Project - Final Report. Observatory Report Series no. 71. Liverpool: Liverpool Public Health Observatory; available at http://www.liv.ac.uk/PublicHealth/obs/ publications/report/Snack_Right_Final_Report2.pdf

24. Benjamin SE, Haines J, Ball SC et al. (2008) Improving nutrition and physical activity in child care: what parents recommend. J Am Diet Assoc 108, 1907-1911.

25. Campbell KJ \& Hesketh KD (2007) Strategies which aim to positively impact on weight, physical activity, diet and sedentary behaviours in children from zero to five years. A systematic review of the literature. Obes Rev $\mathbf{8}, 327-338$.

26. Fitzgibbon ML, Stolley MR, Dyer AR et al. (2002) A Community-based obesity prevention program for minority children: rationale and study design for Hip-Hop to Health Jr. Prev Med 34, 289-297.

27. Health Promotion Service (2003) Good Food in Family Day Care: Improving Nutrition and Food Safety in Family Day Care Schemes. Implementation and Evaluation Report. Sydney: Health Promotion Service, South East Health Service; available at http://www.sesiahs.health.nsw. gov.au/Publications/Health_Promotion/familyDayCare.pdf

28. Heart of Mersey (2006) Nursery Food Provision, Policy and Practice across Cheshire and Merseyside. Report of a Survey of Food Provision in Nurseries across Cheshire and Merseyside to Support the Big Noise Social Marketing 
Project. Liverpool: Heart of Mersey; available at http:// www.heartofmersey.org.uk/uploads/documents/nov_06/ hom_1162897023_HoM_Nursery_Food_Provision,_Po.pdf

29. Matwiejczyk L, McWhinnie JA \& Colmer K (2007) An evaluation of a nutrition intervention at childcare centres in South Australia. Health Promot J Aust 18, 159-162.

30. Mother and Infant Research Unit (2007) The Effectiveness of Public Health Interventions to Improve the Nutrition of Children Aged 2-5 Years. York: Mother and Infant Research Unit, University of York.

31. Office for Standards in Education, Department for Education and Skills \& Food Standards Agency (2004) Starting Early: Food and Nutrition Education of Young Children. Manchester: Ofsted; available at http://www.food.gov.uk/ multimedia/pdfs/ofstedearly.pdf

32. Office for Standards in Education (2006) Food for Thought: A Survey of Healthy Eating in Registered Childcare. Manchester: Ofsted; available at http://www.ofsted.gov. uk/Ofsted-home/Publications-and-research/Browse-all-by/ Care/Childcare/Food-for-thought-a-survey-of-healthy-eatingin-registered-childcare

33. Organix \& Soil Association (2008) Georgie Porgie Pudding and Pie: Exposing the Truth about Nursery Food. Bristol: Organix \& Soil Association; available at http://www. soilassociation.org/LinkClick.aspx?fileticket $=$ P7\%2F0qfiUPe $4 \%$ 3D\&tabid $=388$

34. Romaine N, Mann L, Kienapple K et al. (2008) Menu planning for childcare centres: practices and needs. Can J Diet Pract Res 68, 7-13.
35. Sefton Council (2007) Food and Nutrition in Nursery Settings: Project Report 2006-2007. Southport: Sefton Council, Environmental Protection; available at http:// www.sefton.gov.uk/pdf/epd_nursery\%20analysis.pdf

36. Talvia S, Lagström H, Räsänen $M$ et al. (2004) A randomized intervention since infancy to reduce intake of saturated fat calorie (energy) and nutrient intakes up to the age of 10 years in the Special Turku Coronary Risk Factor Intervention Project. Arch Pediatr Adolesc Med 158, 41-47.

37. Williams CL, Bollella MC, Strobino BA et al. (2002) 'Healthy-start': outcome of an intervention to promote a heart healthy diet in preschool children. J Am Coll Nutr 21, 62-71.

38. Williams CL, Squillace MM, Bollella MC et al. (1998) Healthy Start: a comprehensive health education program for preschool children. Prev Med 27, 216-223.

39. Williams CL, Strobino BA, Bollella M et al. (2004) Cardiovascular risk reduction in preschool children: the 'Healthy Start' project. J Am Coll Nutr 23, 117-123.

40. Green J \& Thorogood N (2007) Qualitative Methods for Health Research. London: Sage Publications.

41. Ritchie J, Lewis J \& Elam G (2003) Designing and selecting samples. In: Qualitative Research and Practice: A Guide for Social Science Students and Researchers, pp. 77-108. [J Ritchie and J Lewis, editors]. London: SAGE Publications.

42. Lloyd-Williams F, Bristow K, Motswama M et al. (2010) Young Children's Food in Liverpool Day Care Settings: A Qualitative Study of Pre-school Nutrition Policy and Practice. Liverpool: University of Liverpool \& Heart of Mersey. 